\title{
The relationship between creative leadership and creative thinking in primary school students
}

\author{
Alexander Petrovich Suhonosov ${ }^{1 *}$, Raphael Camilievich Karneev ${ }^{2}$,Elena Anatolievna \\ Kurganova ${ }^{1}$, and Elena Marikovna Listick $^{1}$ \\ ${ }^{1}$ Moscow City Teacher Training University, Institute of Education and Psychology, Department of \\ Psychology, Moscow, Russia \\ ${ }^{2}$ Bryansk State Academician I.G. Petrovski University, Institute of Education and Psychology, \\ Department of General and Professional Psychology, Bryansk, Russia
}

\begin{abstract}
The paper reveals some aspects of the problem of forming a complex of qualities that characterize the phenomenon of creative leadership in school students. The interest in this problem is explained by the increased need of modern Russian society and its relevance in scientific psychological and pedagogical and socio-psychological problems. The prerequisite for the study was the contradiction between the urgent need for creative leaders in various spheres of production, management, in creative and spiritual life and the absence of a systematic purposeful state policy in this field. At the same time, it is stated that if in foreign science from the beginning of the 1960s, studies of the concept of creative leadership are carried out, but in Russian scientific thought, the concept of creative leadership is still poorly understood from the point of view of its formation. Several aspects of the problem of leadership are reviewed, such as the ability of a leader to lead other people to solve various problems, including creative ones; the concept of creativity is analyzed as the ability to think in an original, non-standard, creative way, to generate innovative cultural products. The phenomenon of creative leadership is considered by the authors, first of all, as a person's expressed ability to lead a group of people to achieve various goals that are important for this group, to implement creative ideas and projects, while the directions, methods, means of their implementation are innovative. The paper presents the results of an experimental study conducted to determine the nature of the relationship between creative leadership and creative thinking. The novelty of the study is determined by the use of an original series of methods that allow for a comprehensive assessment of the formation of creative leadership in school students and the presence of a correlation between the indicators of the creative leadership methodology with various factors characterizing creative thinking.
\end{abstract}

Keywords: personality, leadership, creativity, creative leadership.

\footnotetext{
* Corresponding author: aleks.suhonosov@mail.ru
} 


\section{Introduction}

The problem of studying the phenomenon of creative leadership (CL) is relevant at the present stage of the development of pedagogy and psychology.

Analysis of studies of the problem of creativity carried out by foreign scientists such as E. Weiner [1], E. Bono [2], B.M. Bass [3], T. Elkins, R.T. Keller [4], E. S. Goldshmidt., T.I. Gritskevich, S.M. Meshcheryakova, A.Y. Cherepanov [5], Ki. S. Han, C. Marvin [6], E. Heinla [7], J. Kouzes, B. Z. Posner [8], J. Khatena [9], G. Krumm, A. Filippetti, M Gutierrez [10], B. Sufa [11], C. Mouchiroud, T. Lubart [12], M. D. Mumford, S. Connelly, B. Gaddis [13], E. Torrance [14] and others), as well as by Russian researchers such as D. B. Bogoyavlenskaya [15], I. P. Kaloshina [16], A. M. Matyushkin [17], shows that most of the personal characteristics of a creative person coincide with leadership qualities.

Leadership is a process that can be learned by involving various social and educational factors that develop leadership potential [18].

In Russian science, the concepts of creativity, CL, creative thinking are presented in the works of A.O. Getmanenko [19], A.I. Savenkov [20]; A.P. Sukhonosov, M.Y. Dovgilenko [18].

The purpose of this study is to identify the nature of the relationship between CL and creative thinking. The hypothesis of the study: the more creative thinking and the ability to work creatively with a group are formed, the higher the indicators of CL.

\section{Methods}

To achieve this goal, we used the following methods: the "I am a leader" test by A. N. Lutoshkin; the creativity test by E.P. Torrance; and the CL questionnaire (CLQ) by J. Smith. The study was carried out at the "Chudo Shkola Umnitsa" autonomous non-commercial organization (ANO) in Moscow. The study population consisted of 82 people studying in 3 grades at the age of 9-10 years, 50 girls and 32 boys.

\section{Results and discussion}

In the course of the study, the level of formation of leadership qualities was diagnosed using the "I am a leader" test. The results are presented in Figure 1.

The analysis shows that we did not observe a high level of formation of leadership qualities in the studied group of primary school students: in general, the ability to control themselves is poorly formed in children (scale A, 8.5 points). Indicators on the remaining scales are at the average or above the average level: awareness of the goal (scale B, 13.1 points), the ability to solve problems (scale C, 10.9 points), the presence of a creative approach (scale D, 12 points), influence on others (scale E, 10.6 points), knowledge of the rules of organizational work (scale $F, 12.2$ points), organizational skills (scale $G, 11.2$ points), the ability to work with a group (scale $\mathrm{H}, 11.7$ points). It should be noted that the indicator of goal awareness is at the highest level of the rest of the results obtained. The integral indicator of leadership in the group is 90.2 points, which corresponds to the average level of formation of leadership qualities in the group. 


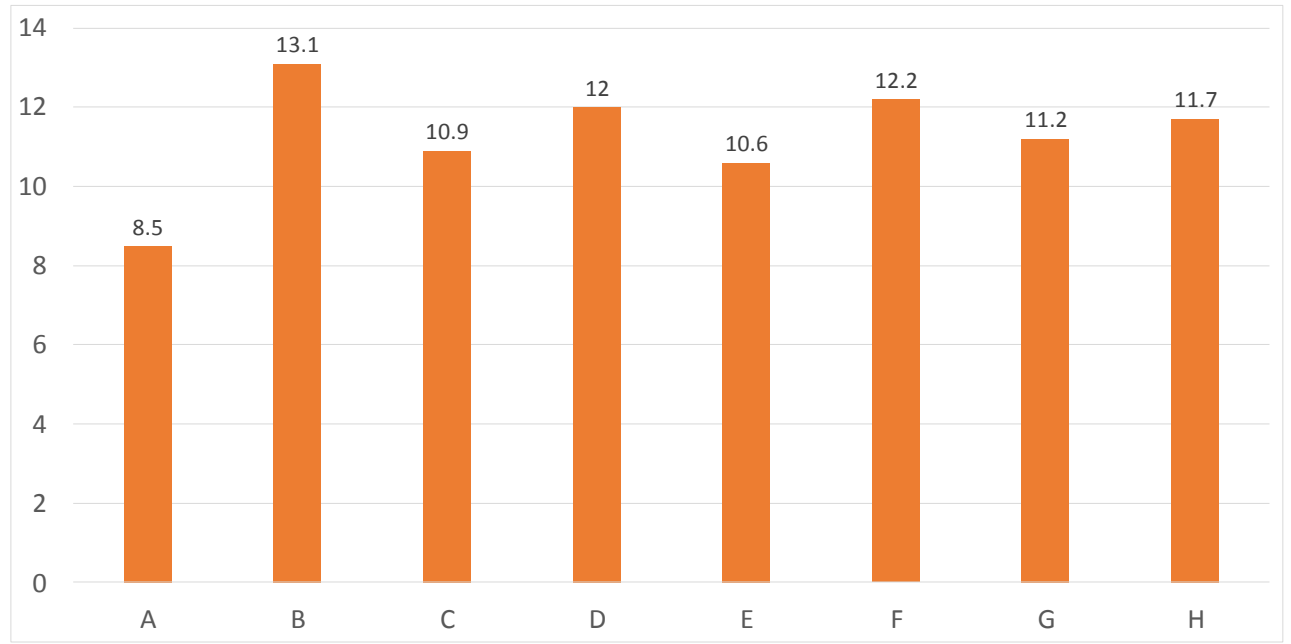

Fig. 1. The expression of the level of formation of leadership qualities among primary school students (group average in points)

Since this sample did not demonstrate a high level of leadership qualities, and the level above average was diagnosed in 2 students, for a more detailed analysis, we divided the sample into two groups. The first consisted of students with low and below-average levels of leadership (20 people, $24.4 \%$ ), and the second group included the students with average and above-average levels (62 people, 75.6\%). The integral indicator in the group with a low and below-average level of leadership is 73 points, and in the center and above-average group, it is 95.6 points.

The results of the level of formation of leadership qualities in two groups of primary school students are presented in Figure 2.

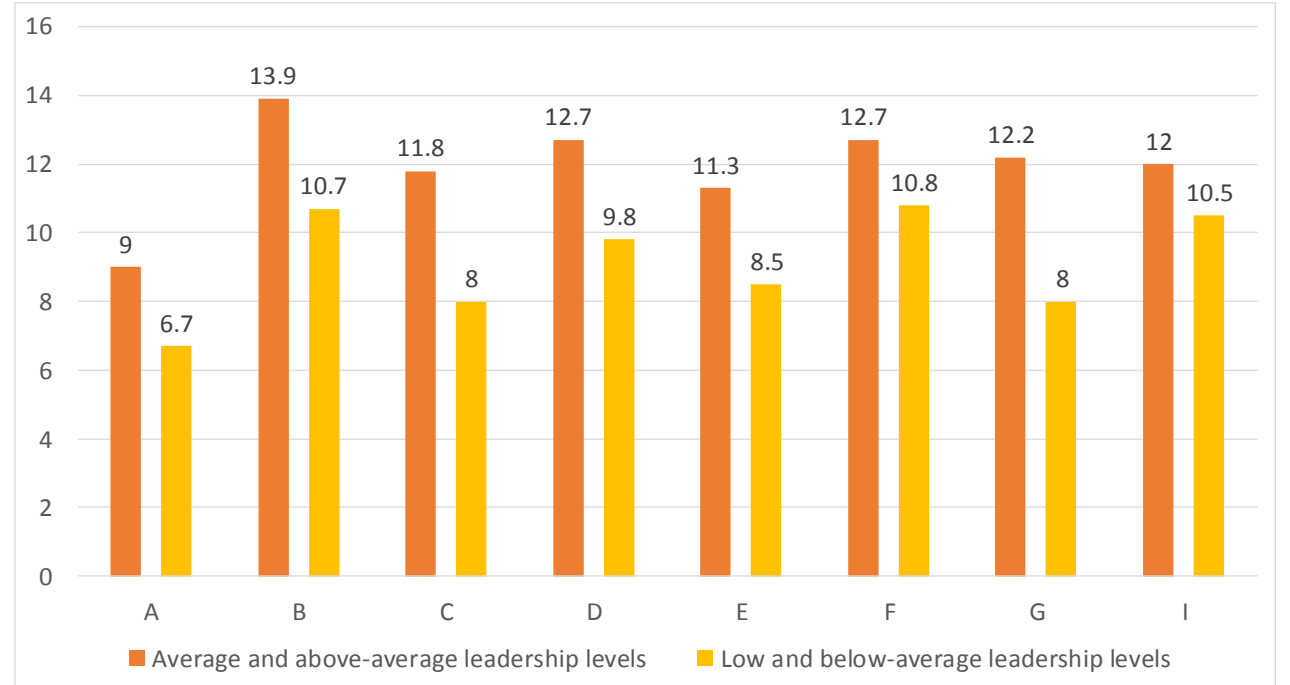

Fig. 2. Expression of leadership qualities in primary school students with different levels of leadership (in points)

In the group with a low indicator of leadership formation, such components as the ability to control oneself (scale A, 6.7 points), the ability to solve problems (scale C, 8 points), the influence on others (scale E, 8.5 p.) and organizational skills (scale GF, 8 p.) are expressed 
at a low level. The rest of the indicators are at the average level. In the group with a high level of leadership qualities, only the indicator of the ability to control oneself was expressed at a low level (scale A, 9 points). The rest of the scales are at the average level and above the average.

Further, the diagnostics of the components of creativity was carried out using the second subtest of the series of tests of creative thinking by E.P. Torrance (the results are expressed on the Torrance scale or T-scale).

The analysis of the results was carried out in two groups of primary school students with different levels of formation of leadership qualities (Fig. 3).

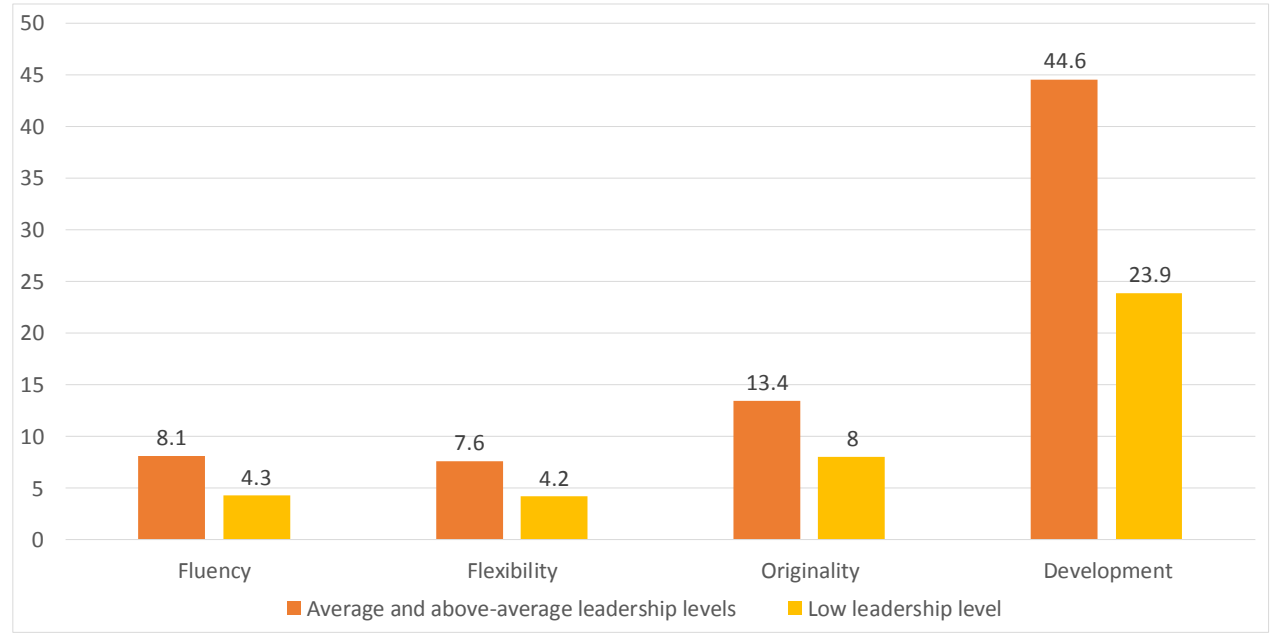

Fig. 3. Expression in points of the components of creative thinking in primary school students with different levels of leadership (group average values in points)

In the group of school students with an average and above-average level of leadership, the indicator of fluency (productivity) of thinking corresponds to 8.1 points, which indicates the age norm. Similar levels of formation were also revealed on other scales: flexibility (7.6 points), originality ( 13.4 points, 62 by T-scale), development ( 44.6 points, 58 by T-scale).

In the group with a low level of leadership, a level below the age norm of the parameters of fluency and flexibility of thinking was revealed (4.3 and 4.2 points, respectively). The level of originality equals 8 points ( 42 by T-scale) and development equals 23.9 points (53 by T-scale) These results also correspond to the age norm, and as a whole, the indicators tend to decrease.

Using the CLQ questionnaire for high and low levels of CL, the following indicators were obtained (Fig. 4). 


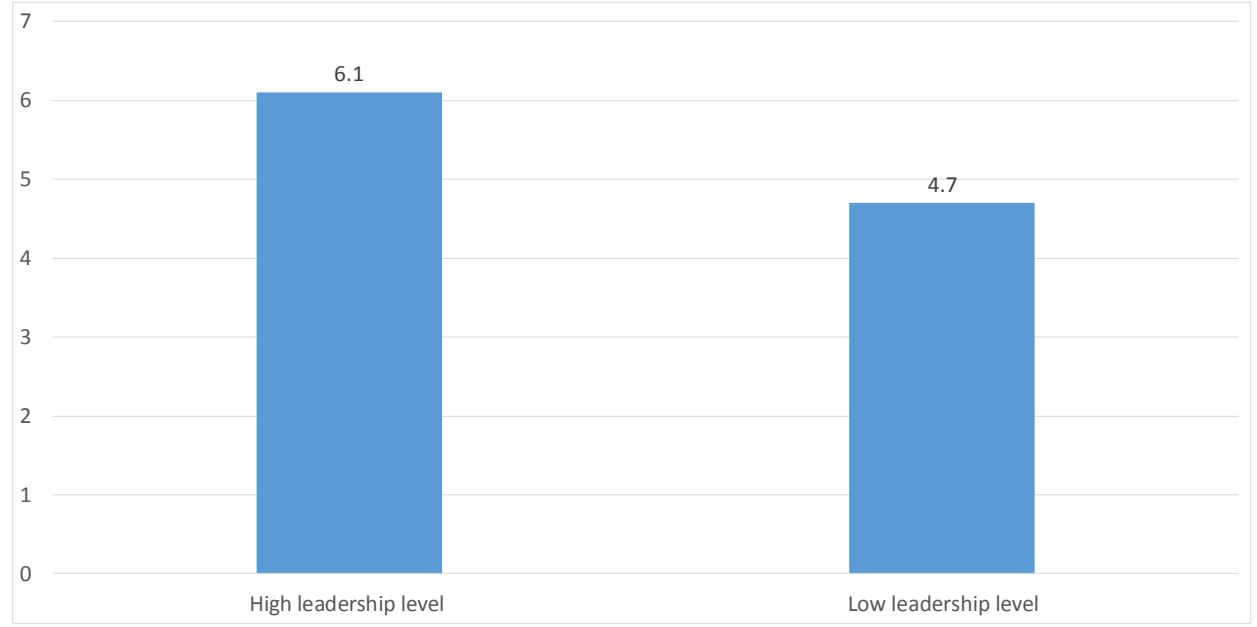

Fig. 4. Levels of formation of CL in groups with different levels of formation of leadership qualities (group average values in points)

CL is in the average range of values; at the same time, the indicators in the group with a low level of leadership tend to decrease (4.7 points), while in the group with a high level of leadership they tend to increase (6.1 points).

Comparative data on the levels of formation of leadership qualities in groups of primary school students with different levels of CL is presented in Figure 5.

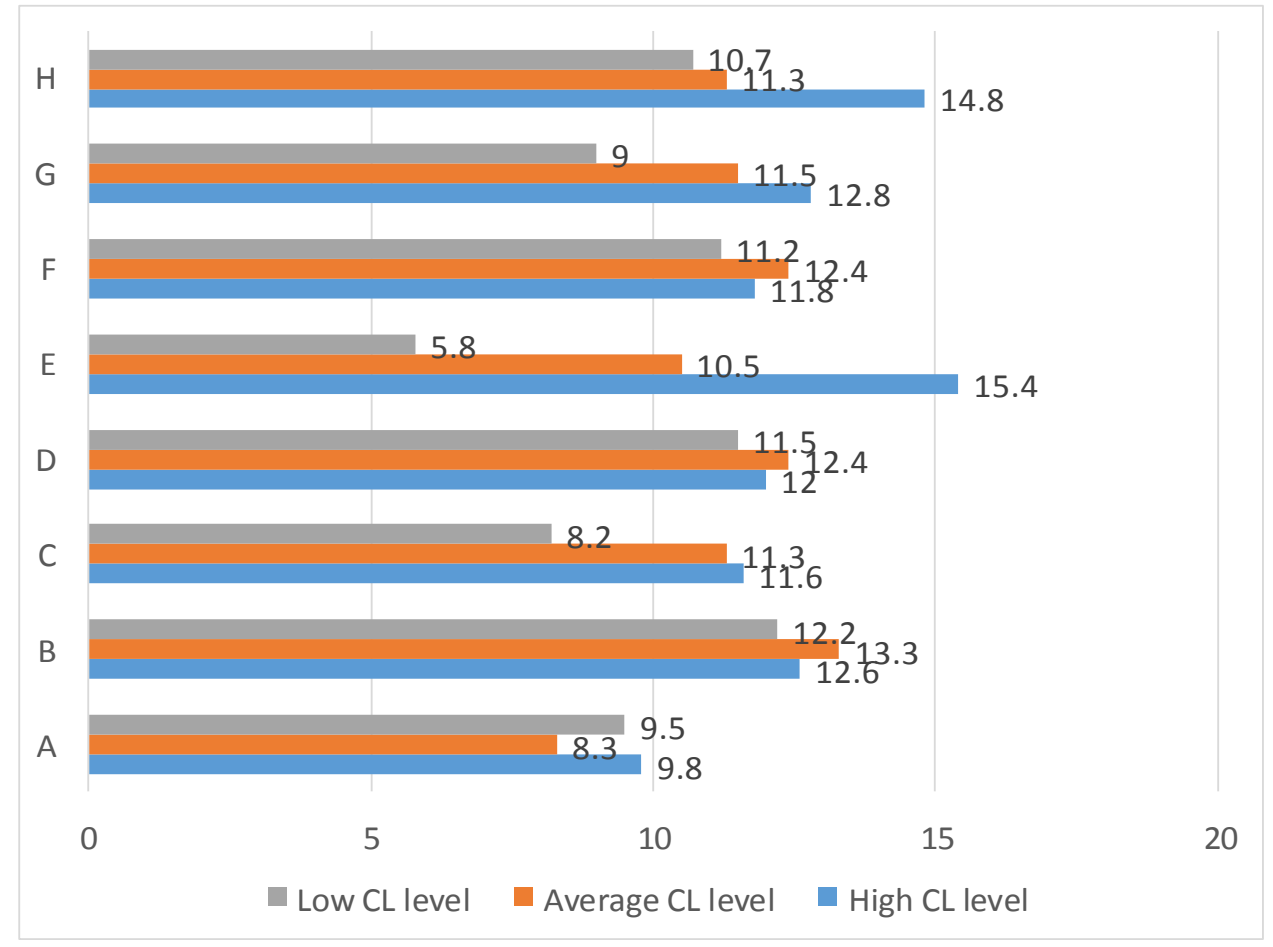

Fig. 5. Levels of formation of leadership qualities in groups with different levels of CL (group average values in points) 
The analysis of the presented results shows that with a low level of CL, the leadership qualities such as influence on others (E, 5.8 points), ability to solve problems (C, 8.2 points), organizational skills ( $\mathrm{G}, 9$ points), and the ability to control oneself (A, 9.5 points) are less likely to be expressed on a high level.

With an average level of formation of CL in the sample under study, the ability to control oneself is poorly developed (A, 8.3 points), while the other indicators are at the average and above-average level.

With a high level of CL, all qualities are at an average and high levels which is expressed by the results on the following scales: influence on others (E, 15.4 points), and the ability to work with a group (H, 14.8 points).

The results of determining the integral indicators of the general level of leadership in groups with different levels of CL are shown in Figure 6.

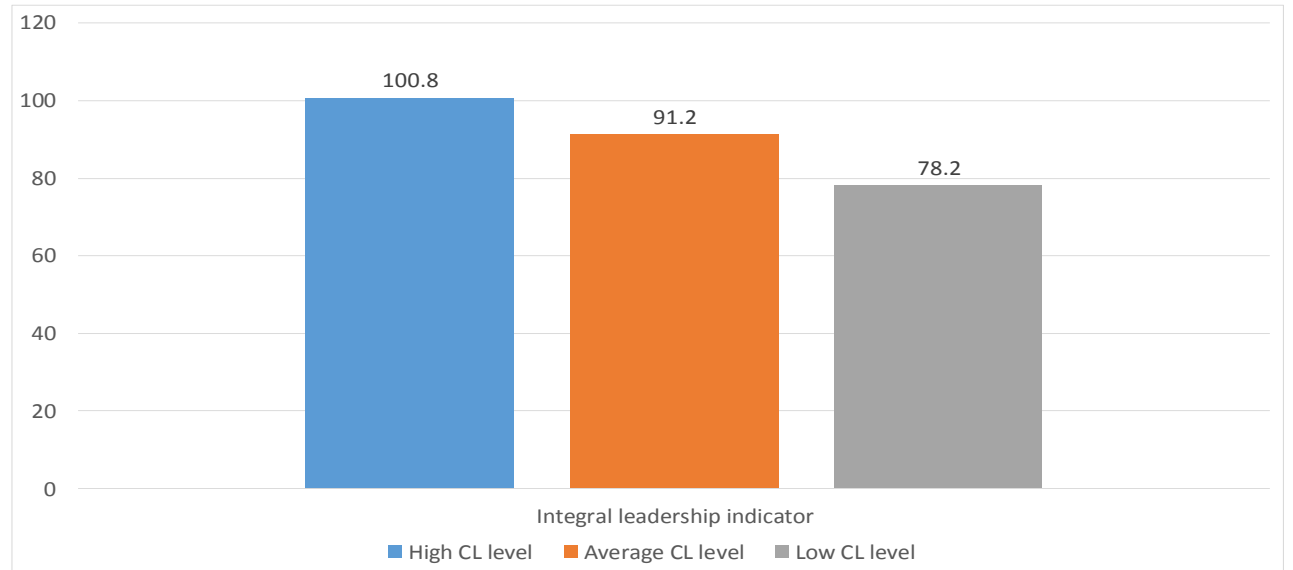

Fig. 6. Integral indicator of leadership in groups with different levels of CL (group average values in points)

The analysis of the presented results shows that the most pronounced general leadership qualities are observed in the group of school students with a high level of CL formation (100.8 points). This group is followed by the group with an average level of CL (91.2 points) and the group with a low level of CL (78.2 points). Thus, one can see the dynamics of a decrease in the indicators of general leadership with a decrease in the indicators of CL.

We performed an analysis of indicators of creativity in all three groups (Fig. 7).

In the group of school students with a low level of CL, the indicator of fluency (productivity) of thinking corresponds to 5.5 points, which indicates a low level that does not reach the age norm. Values corresponding to the normative data were obtained on the scales of flexibility and originality (7 points and 9.5 points respectively). On the scale of development, we obtained a result approaching the lower threshold of the age norm $(21.2$ points, 44 by T-scale).

In the group with an average level of CL, a lower threshold of the normative level of fluency ( 7 points), a normal level of flexibility (6.4 points), originality (11.9 points, 55 by Tscale), and development (39.1 points 55 by T-scale) were observed.

In the group with a high level of $\mathrm{CL}$, we also observed the lower threshold value of the normative level of fluency (7.2 points), the normal level of flexibility (6.2 points), originality (12.2 points, 56 by T-scale), and development (38.8 points, 55 by T-scale).

In general, the indicators of the components of creativity are similar in the groups with the average and high levels of CL, while in the third group their clear decline is observed. 
Correlation analysis carried out using the method of C.E. Spearman showed the relationship of indicators of the adapted CLQ with such parameters as creativity, originality of thinking, influence on others, and organizational skills.

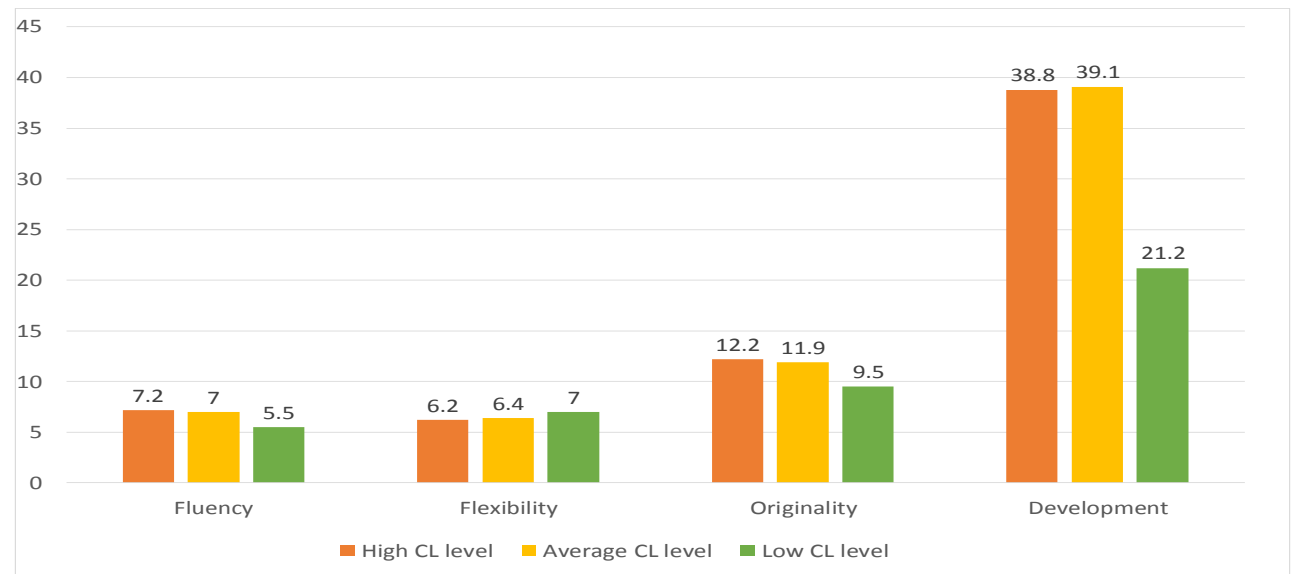

Fig. 7. The expression of the components of creativity in groups with different levels of formation of CL (average group values in raw points)

In particular, positive bilateral relationships were revealed according to the following scales: the CL scale is associated with the creative approach scales $(0.569$, at $\mathrm{p} \leq 0.01)$, influence on others $(0.488$, at $\mathrm{p} \leq 0.01)$, organizational skills $(0.319$, at $\mathrm{p} \leq 0.05)$, originality of thinking $(0.387$, at $\mathrm{p} \leq 0.05)$.

The goal awareness scale positively correlates with the integral indicator of leadership $(0.350$, at $\mathrm{p} \leq 0.05)$ and all components of creativity: fluency $(0.419$, at $\mathrm{p} \leq 0.01)$, flexibility $(0.359$, at $\mathrm{p} \leq 0.05)$, originality $(0.512$, at $\mathrm{p} \leq 0.01)$ and development $(0.464$, at $\mathrm{p} \leq 0.01)$.

We also observed a correlation of general leadership indicators $(0.349$, at $\mathrm{p} \leq 0.05)$, fluency $(0.419$, at $\mathrm{p} \leq 0.01)$, flexibility $(0.354$, at $\mathrm{p} \leq 0.05)$, originality $(0.428$, at $\mathrm{p} \leq 0.01$ ), and development $(0.467$, at $\mathrm{p} \leq 0.01)$ with the indicators of the scale the ability to solve problems.

The Torrance figure test also shows significant connections between the scales. Thus, the fluency scale correlates with the flexibility $(0.534$, at $\mathrm{p} \leq 0.01)$, originality $(0.538$, at $\mathrm{p} \leq 0.01)$, and development $(0.472$, at $\mathrm{p} \leq 0.01)$ scales. The flexibility scale is associated with originality $(0.620$, at $\mathrm{p} \leq 0.01)$ and development $(0.492$, at $\mathrm{p} \leq 0.01)$, and the originality scale is also associated with development $(0.398$, at $\mathrm{p} \leq 0.05)$.

Based on the results of the study, it seems that CL as a socio-psychological phenomenon combines the characteristics of the concepts of leadership and creativity. A creative leader is a person who has creative potential. This kind of leader leads the creative process, but at the same time they are not alone as a leader and they have followers who fully support their ideas and directions of activities.

\section{Conclusion}

Thus, the most important features that determine the level of CL are the ability to be creative, originality of thinking, a high level of influence on others, and formed organizational skills.

The degree of awareness of one's goals and desires is influenced by general leadership qualities and the formation of all components of creative thinking; with high levels of general leadership, the ability to solve problems increases, and leaders have more developed creative abilities, and this, in turn, determines a high level of organizational skills. 


\section{References}

1. E. Weiner, Geografiya genialnosti: gde i pochemu rozhdayutsya velikie idei [The geography of genius: a search for the world's most creative places] (Alpina Publisher, Moscow, 2017)

2. E. de Bono, Uchite svoego rebenka myslit [Teach your child how to think] (translated from English) (Popurri, Minsk, 2008)

3. B.M. Bass, Stogdill's handbook of leadership: theory, research, and managerial applications (FreePress, New York, Collier Macmillan, London, 1990)

4. T. Elkins, R.T. Keller, The Leadership quarterly, 14(4-5), 587-606 (2003). https://doi.org/10.1016/S1048-9843(03)00053-5

5. E.S. Goldshmidt, T.I. Gritskevich, S.M. Meshcheryakova, A.Y. Cherepanov, EpSBS, 35, 383-394 (2017). https://doi.org/10.15405/epsbs.2018.02.45

6. Ki.S. Han, C. Marvin, Gifted child quarterly, 46(2), 98-109 (2002)

7. E. Heinla, YOUNG, 14(3), 235-255 (2006). https://doi.org/10.1177/1103308806065818

8. J. Kouzes, B.Z. Posner, The leadership challenge (Hoboken, Wiley, 2012)

9. J. Khatena, Gifted child quarterly, 18(3), 202-209 (1974)

10. G. Krumm, A.V. Filippetti, M. Gutierrez, Thinking Skills and Creativity, 29, 185-195 (2018). https://doi.org/10.1016/j.tsc.2018.07.0062018

11. B. Sufa, Knowledge of early education teachers about creativity and the model of the ideal student in 6th SWS International scientific conferences on social sciences 2019, Conference proceedings, 717-726 (2019)

12. C. Mouchiroud, T. Lubart, The Journal of genetic psychology, 162(4), 382-401 (2001)

13. M.D. Mumford, Sh. Connelly, B. Gaddis, The Leadership quarterly, 14(4-5), 411 (2003). https://doi.org/10.1016/S1048-9843(03)00045-6

14. E.P. Torrance, Gifted Child Quarterly, 7(4), 135-145 (1963)

15. D.B. Bogoyavlenskaya, Psikhologiya tvorcheskikh sposobnostei [Psychology of creativity] (Izdatelskii tsentr Akademiya, Moscow, 2002)

16. I.P. Kaloshina, Upravlenie tvorcheskoi deyatelnostyu [Creative management] (YuNITI-DANA, Moscow, 2018)

17. A.M. Matyushkin, Myshlenie, obuchenie, tvorchestvo [Thinking, learning, creativity] (Izdatelstvo Moskovskogo psikhologo-sotsialnogo instituta, Moscow, Izdatelstvo NPO MODEK, Voronezh, 2003)

18. A.P. Sukhonosov, M.Y. Dovgilenko, Izvestiya instituta pedagogiki i psikhologii obrazovaniya, 1, 47-50 (2019)

19. A.O. Getmanenko, Sibirskii Psikhologicheskii Zhurnal, 56, 86-99 (2015)

20. A.I. Savenkov, Shkolnyi psikholog, 30, 11-22 (2004) 